\title{
Optimal Mixture Ratios of Biodiesel Ethanol Diesel for Diesel Engines*
}

\author{
Jun Li, Chao Guo, Wenbin Wang, Zhuojian Wu \\ Chongqing Jiaotong University, Chongqing, China \\ E-mail:cqleejun@sina.com,guogroup@126.com,wangwenbin7423@163.com \\ Recieved September 27, 2011; revised October 28, 2011; accepted November 9, 2011
}

\begin{abstract}
In this paper, we study the best-mixture ratio of biodiesel-ethanol-diesel for diesel engines. The simulation results show that the integrated indexes including engine power, cost-effectiveness and emission properties are rather better with different optimizing index when the ratio of bio-diesel, ethanol and diesel are 71.58: 2.72:25.70 and 50:2.4127:47.5873.
\end{abstract}

Keywords: Diesel Engine, Biodiesel, Ethanol, Best-Mixture Ratio, Integrated Indexes

\section{Introduction}

Developing new energy car is the top research issue in the automobile industry, for the energy crisis and air pollution had become severe global problems [1]. In China, the project of exploring biodiesel as an automobile substitutable fuel has been formulated to achieve the nation energy developing plan in biology liquid fuel. In this paper the ethanol is ejected into the biodiesel-diesel with high mixture ratio, the mixture ratio of biodiesel is over $50 \%$, as an assistant burning material. The power, cost-effectiveness performance and SOOT, $\mathrm{NO}_{\mathrm{x}}$ emissions property of diesel engine is analyzed and researched. And the torque fuel consumption rate, $\mathrm{NO}_{\mathrm{x}}$ and SOOT emissions are chosen as the integrated indexes for the best mixture ratio of biodiesel-ethanoldiesel.

\section{Simulation Test and Uniformity Design Principle}

The diesel engine with biodiesel-ethanol-diesel fuel in different mixture ratio is simulated by using GT-Power [2] to research the best mixture ratio of biodiesel-ethanol-diesel for optimizing the power, cost-effectiveness permance and SOOT, $\mathrm{NO}_{\mathrm{x}}$ emissions property of diesel engine.

\subsection{Introduction of Uniformity Design Principle}

Uniformity design principle is an experiment design

"Supported by: Foundation Project of the Key Laboratory of Chongqing Communication Engineering (2008CQJY002); Education and Teaching Reform Project of Chongqing CSTC, China (No. 0903070). method, put forward by Professor Fang Kai Tai and Wang Yuan in China Academy of Scientist, Application mathematics department in 1970s. The process of uniformity design principle method includes steps as following, 1) ensuring the experiment aims and evaluation indexes, 2) choosing experiment factors, 3) ensuring the level of each factor, 4) choosing uniformity design table and assign relative factors, 5) making experiment schemes and operations, 6) analyzing the experimental results.

\subsection{Choosing of Factors, Level and Optimization Aims}

1) Choosing experiment factors, the mass fractions of ethanol and biodiesel are chosen to be experimental factor 1 and 2 respectively. For the diesel ratio in mixture is fixed as soon as the ratios of biodiesel and ethanol are defined, it is needn't to take the mass fraction of diesel as experimental factor as well. Because the engine runs under variable modes practically, it is unreliable to ensure the best-mixture ratio under a single mode $[3,4]$. Besides, the revolution and load alteration are taken consideration in building math model to ensure the best mixture ratio. The revolution and load are chosen to be factor 3 and 4 .

2) Determining the factor level, in this paper that the assistant fuel, ethanol, is ejected in the mixture fuel with high mixture ratio is researched. So the biodiesel factor levels are chosen at $50 \%, 60 \%, 70 \%, 80 \%, 90 \%$. The ethanol factor levels are at $2.5 \%, 5 \%, 7.5 \%$, and $10 \%$. Considering the various practical modes the revolution 
levels are chosen at $800,1000,1400,1800,2200 \mathrm{r} / \mathrm{m}$. the load levels are at 25\%, 50\%,75\% and full load.

\subsection{Diesel Engine Simulation Model and Fuel-Base}

Supercharging \& middle cooling diesel engine is researched in this paper, and its technical parameters are shown in Table 1.

Table 1. The main technical parameters of diesel engine.

\begin{tabular}{cc}
\hline Engine Form & $\begin{array}{c}\text { Six-cylinder, Four-stroke, } \\
\text { Supercharging \& middle cooling } \\
\text { diesel engine }\end{array}$ \\
\hline $\begin{array}{c}\text { Cylinder diameter } \times \text { Stroke } \\
\text { length } \\
\text { Compression ratio }\end{array}$ & $114 \mathrm{~mm} \times 135 \mathrm{~mm}$ \\
Total cylinders cubage/L \\
Maximum \\
torque/Revolution \\
Rating power/Revolution
\end{tabular}

The diesel engine is predigested different models such intake system, exhaust system, cylinder, crankcase, ejecting device, middle cooler, circumstance and the relative pipe among them based on the parameters above all. The diesel model seems as Figure 1.

In this paper the biodiesel composes of saturated and unsaturated fatty acid methyl ester such as, palmitic acid methyl ester, stearic acid methyl ester, oleic acid methyl ester, linoleic acid methyl ester, linolenic acid methyl ester [5-8]. And their structure forms are following as:

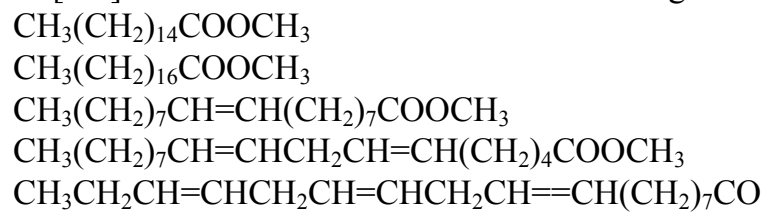

Their chemical forms and ratios are shown in Table 2.

\section{Analyzing Simulation Results}

Simulation experiment is carried out with GT-Power according the experiment scheme, and experimental re-

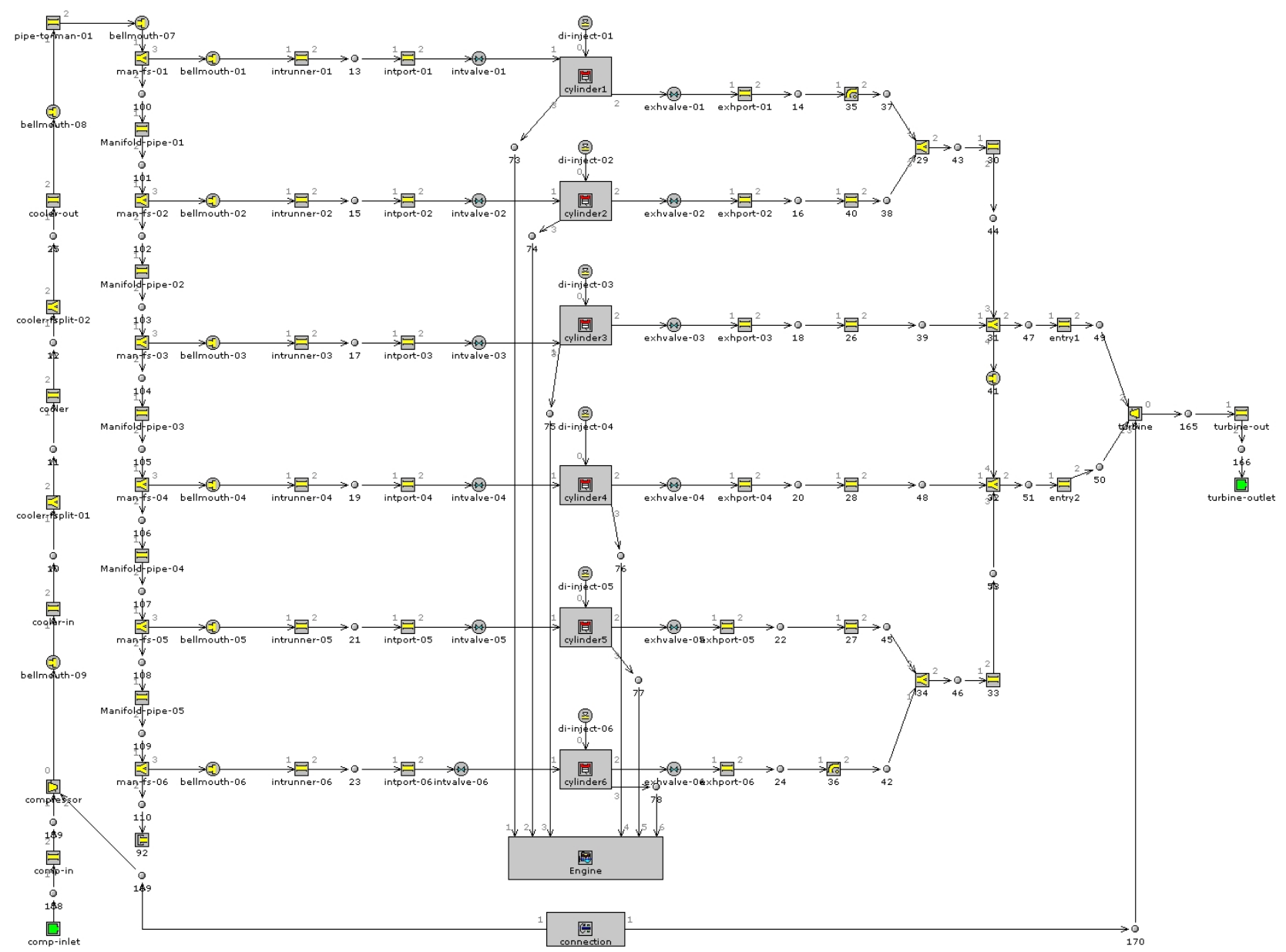

Figure 1. Diesel engine simulation model diagram. 
sults (torque, BSFC, $\mathrm{NO}_{\mathrm{x}}$, SOOT) are shown in Table 3.

\subsection{Ensuring Integrated Index}

The experiment results shown in Table 3 dedicate that the optimization aim is a multi-index, which needs to be quantitated firstly, and then optimized comprehensively. Integrated evaluation method based on weighting factor is adopted to acquire the integrated index value yi $[3,4]$, whose computing formula is as following.

$$
\mathrm{yi}=\mathrm{bi1} \times \mathrm{yi} 1+\mathrm{bi} 2 \times \mathrm{yi} 2+\cdots+\mathrm{b} i j \times \mathrm{y} i j
$$

Therein, bij are the coefficient. Yij are the experiment indexes. $i$ expresses the $i$ th experimental level. $j$ expresses the $j$ th experiment index.

The total weighting factor is supposed as 100. And then the weighting factor of every index would be evaluated as bij, determined by the index's weight compared with total weighting factor 100. After analyzing the comparative weight of different index comprehensively based on professional knowledge, there are two series of the integrated weighting evaluation are set in this paper. In the first set the weights of torque, fuel consumption rate, $\mathrm{NO}_{\mathrm{x}}$ and SOOT all are 25. In the second set the weight of torque is 15 , that of fuel consume rate is 35 , that of $\mathrm{NO}_{\mathrm{x}}$ is 15 , and that of SOOT is 35 . The values of integrated index Y1 and Y2 are contra posed to the first and second set respectively.

The difference between the maximum and the minimum of every experiment is its variation spectrum $\mathrm{k}$. The $\mathrm{k}$ of torque is 670.544 , that of fuel consumption rate is 126.504, and that of $\mathrm{NO}_{\mathrm{x}}$ is 209.3779, while that of SOOT is 2.101513 .

The coefficient is computed by following formula.

$$
\text { bij = Weight } / \mathrm{k}
$$

Computing the integrated evaluation of the weighting factor is corresponded to evaluate every experiment result. The values of different indexes should be supposed as lesser numbers at the same class before calculating the integrated index value in case of wrong in calculating. Besides, the value of torque index should be as larger as possible, and the values of fuel consume rate, $\mathrm{NO}_{\mathrm{x}}$ and SOOT are as small as possible. The value of torque is supposed as a minus to acquire the minimums of all indexes unifiedly. The acquired integrated evaluations based on weighting factor are $\mathrm{Y} 1$ and $\mathrm{Y} 2$, as shown in Table 3.

Table 2. Basic information of the biodiesel [6,7].

\begin{tabular}{cccc}
\hline Name & Chemical Form & Molecular Weight & Ratio (\%) \\
\hline palmitic acid methyl ester & $\mathrm{C}_{17} \mathrm{H}_{34} \mathrm{O}_{2}$ & 270.45 & 10.74 \\
stearic acid methyl ester & $\mathrm{C}_{19} \mathrm{H}_{38} \mathrm{O}_{2}$ & 298.50 & 4.28 \\
oleic acid methyl ester & $\mathrm{C}_{19} \mathrm{H}_{36} \mathrm{O}_{2}$ & 296.49 & 24.03 \\
linoleic acid methyl ester & $\mathrm{C}_{19} \mathrm{H}_{34} \mathrm{O}_{2}$ & 294.48 & 54.23 \\
linolenic acid methyl ester & $\mathrm{C}_{19} \mathrm{H}_{32} \mathrm{O}_{2}$ & 292.46 & 6.72 \\
\hline
\end{tabular}

\begin{tabular}{|c|c|c|c|c|c|c|c|c|c|c|}
\hline $\begin{array}{l}\text { Level/ } \\
\text { Factor }\end{array}$ & $\begin{array}{c}\text { Ethanol mass } \\
\text { fraction } \\
\mathrm{X} 1 / \%\end{array}$ & $\begin{array}{c}\text { Biodiesel mass } \\
\text { fraction } \\
\text { X } 2 / \%\end{array}$ & $\begin{array}{c}\text { Rev } \\
\text { X3/RPM }\end{array}$ & $\begin{array}{l}\text { Load } \\
\text { X4/\% }\end{array}$ & $\begin{array}{l}\text { Torque } \\
\mathrm{y} 1 / \mathrm{N} \cdot \mathrm{m}\end{array}$ & $\begin{array}{c}\text { BSFC } \\
\mathrm{y} 2 / \mathrm{g} /(\mathrm{kW} \cdot \mathrm{h})\end{array}$ & $\begin{array}{c}\mathrm{NO}_{\mathrm{x}} \\
\mathrm{y} 3 / \mathrm{ppm}\end{array}$ & $\begin{array}{l}\text { SOOT } \\
\text { y4/ppm }\end{array}$ & $\begin{array}{c}\text { Integrated } \\
\text { index value } \\
\text { Y1 }\end{array}$ & $\begin{array}{c}\text { Integrated } \\
\text { index value } \\
\text { Y2 }\end{array}$ \\
\hline N1 & 5 & 70 & 1000 & 75 & 598.959 & 235.123 & 105.002 & 2.02225 & 60.7289 & 92.8554 \\
\hline $\mathrm{N} 2$ & 5 & 50 & 1000 & 25 & 188.958 & 235.577 & 4.93408 & 1.09812 & 53.1629 & 79.5927 \\
\hline N3 & 2.5 & 90 & 800 & 50 & 418.092 & 259.641 & 30.4608 & 0.636468 & 46.9316 & 75.2649 \\
\hline N4 & 2.5 & 80 & 1800 & 75 & 544.014 & 259.641 & 93.4912 & 1.24741 & 57.0307 & 87.1386 \\
\hline N5 & 10 & 60 & 800 & 100 & 829.374 & 239.685 & 214.312 & 0.529577 & 48.3345 & 71.9343 \\
\hline N6 & 5 & 90 & 2200 & 100 & 731.667 & 282.368 & 130.981 & 0.775017 & 53.3824 & 84.047 \\
\hline N7 & 2.5 & 70 & 2200 & 25 & 179.289 & 361.627 & 57.3555 & 2.63109 & 102.9293 & 143.97 \\
\hline N8 & 5 & 60 & 1400 & 50 & 478.244 & 240.247 & 119.896 & 2.06413 & 68.5187 & 98.738 \\
\hline N9 & 10 & 90 & 1400 & 25 & 199.145 & 265.033 & 17.0314 & 1.31078 & 62.5785 & 91.9229 \\
\hline N10 & 7.5 & 60 & 1800 & 75 & 561.163 & 253.786 & 87.1341 & 1.37306 & 55.9699 & 86.7723 \\
\hline
\end{tabular}

Table 3. Results of experiment and integrated indexes. 


\subsection{Quadratic Multinomial Regression Model}

The quadratic multinomial regression models of integrated indexes in Table 3 are acquired by statistics software and their formula are as following.

$$
\begin{aligned}
\mathrm{Y} 1= & -7045.01+2656.13 * \mathrm{X} 1-197.90 * \mathrm{X} 2 \\
& +5.35 * \mathrm{X} 3+89.84 * \mathrm{X} 4-86.70 * \mathrm{X} 1 * \mathrm{X} 1 \\
& +2.31 * \mathrm{X} 2 * \mathrm{X} 2+0.025 * \mathrm{X} 4 * \mathrm{X} 4 \\
& -12.98 * \mathrm{X} 1 * \mathrm{X} 2-0.31 * \mathrm{X} 1 * \mathrm{X} 3 \\
& -4.41 * \mathrm{X} 1 * \mathrm{X} 4-0.011 * \mathrm{X} 2 * \mathrm{X} 3 \\
& -0.56 * \mathrm{X} 2 * \mathrm{X} 4-0.023 * \mathrm{X} 3 * \mathrm{X} 4 \\
\mathrm{Y} 2= & -649.08+97.06 * \mathrm{X} 1+5.09 * \mathrm{X} 2 \\
& +0.48 * \mathrm{X} 3-2.81 * \mathrm{X} 4-3.44 * \mathrm{X} 1 * \mathrm{X} 1 \\
& +0.008 * \mathrm{X} 2 * \mathrm{X} 2+0.045 * \mathrm{X} 4 * \mathrm{X} 4 \\
& -0.68 * \mathrm{X} 1 * \mathrm{X} 2-0.002 * \mathrm{X} 1 * \mathrm{X} 3 \\
& -0.12 * \mathrm{X} 1 * \mathrm{X} 4-0.003 * \mathrm{X} 2 * \mathrm{X} 4 \\
& -0.002 * \mathrm{X} 3 * \mathrm{X} 4
\end{aligned}
$$

\subsection{Obtaining the Best Mixture Ratio}

The regression formula shows that the integrated index is related to mixture ratio, revolution and load. It means the integrated index is only related to revolution and load when the mixture ratio is fixed. The function relationship among the integrated index, revolution and load vary from each mixture ratio. In $3 \mathrm{D}$ coordinate series, the revolution, load and integrated index are respectively supposed as $\mathrm{X}$ axis, $\mathrm{Y}$ axis and $\mathrm{Z}$ axis. The bend roof cylinder could be computed by $\mathrm{z}=\mathrm{f}(\mathrm{x}, \mathrm{y})(\mathrm{x} 1 \leq \mathrm{x} \leq \mathrm{x} 2$, $\mathrm{y} 1 \leq \mathrm{y} \leq \mathrm{y} 2)$. Therein, $\mathrm{x} 1$ and $\mathrm{x} 2$ are the maximum and minimum of revolution respectively. And y1 and y2 are the maximum and minimum of load. The cubage of the bend roof cylinder $\left(\mathrm{V}_{\text {integrated index }}\right)$ can be used to evaluate the value of the integrated index under the prefixed mixture ratio. The smaller the cubage is, the smaller the integrated index value is at the same mixture ratio.

Taking consideration of the various mode of engine, practically, the final integrated index value judged by the above way is comprehensive and comparative reasonable. The $V_{\text {integrated index }}$ with different mixture ratio could be obtained by double integral $[9,10]$. The relationship among $\mathrm{V}_{\text {integrated index }}$, ethanol and biodiesel are shown in Figures 2 and $\mathbf{3}$ corresponding to the first and second scheme respectively. The minimum of $\mathrm{V}_{\text {integrated index }}$ is $\mathrm{X} 1$ $=2.72$ and $\mathrm{X} 2=71.58$ when the first scheme is adopted. And when the second scheme is adopted the minimum of $\mathrm{V}_{\text {integrated index }}$ is $\mathrm{X} 1=2.4127, \mathrm{X} 2=50$. This dedicates the best mixture ratio of bio-diesel, ethanol and diesel are 71.58:2.72:25.70 and 50:2.4127:47.5873 when the torque, fuel consumption rate, $\mathrm{NO}_{\mathrm{x}}$ and SOOT emissions

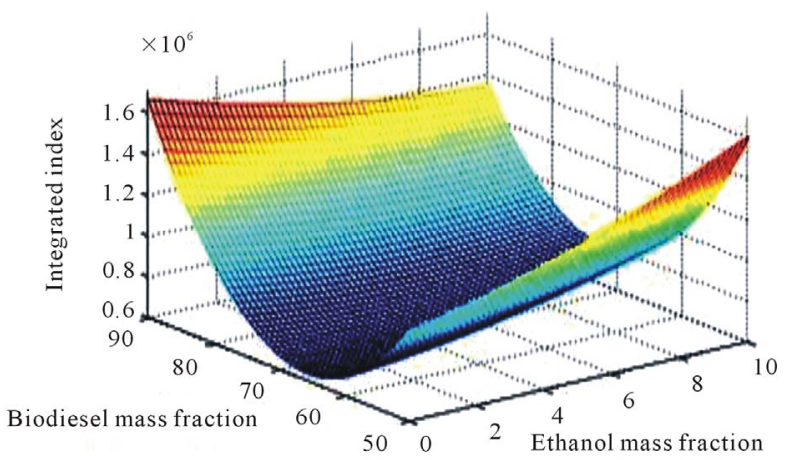

Figure 2. Relation between Integrated optimization index (option one) on all kinds of conditions and the proportion of ethanol and biodiesel.

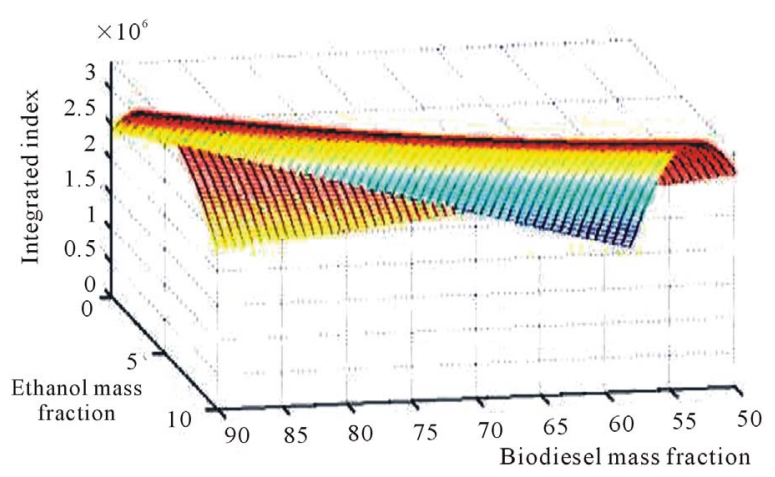

Figure 3. Relation between Integrated optimization index (option two) on all kinds of conditions and the proportion of ethanol and biodiesel.

are considered under all modes comprehensively.

\section{Conclusions}

1) The diesel engine power, cost-effectiveness and emission vary between good and bad as the biodiesel-ethanoldiesel mixture with different mixture ratio is burning in it under different revolution and load.

2) After analyzing the torque, fuel consumption rate, $\mathrm{NO}_{\mathrm{x}}$ and SOOT emissions with two weighting factor schemes, the results show that the integrated index including engine power, cost-effectiveness and emission properties is rather better with different optimizing index when the ratio of bio-diesel, ethanol and diesel are 71.58:2.72:25.70 and 50:2.4127:47.5873.

\section{Acknowledgements}

The work was supported by Foundation Project of the Key Laboratory of Chongqing Communication Engineering (2008CQJY002) and by Education and Teaching Reform Project of Chongqing CSTC, China (No.0903070). 


\section{References}

[1] D. X. Su, "Natural Gas Hydrate Brings to Energy Program of China: New Energy of China," March 2010. http://www.in-en.com/newenergy/html

[2] Gamma Technologies, "GT-SUITE Flow Reference Manual,” Version 6.1, August 2005.

[3] Y. Y. Lee and C. R. Hu, "Experiment Design and Data Processing," Chemical Industry Press, Beijing, 2008.

[4] Y. B. Qiu, "Experiment Design and Data Processing," University of Science and Technology of China Press, Hefei, 2008.

[5] J. H. Wu, "Experimental Investigation of Combustion and Emissions on a Turbocharged DME Engine," Shanghai Jiaotong University, Shanghai, 2007.

[6] W. Yuan, A. C. Hansen and Q. Zhang, "Predieting the Physieal Properties of Biodiesel for Combustion Modeling,"
Transaetion of the ASAE, Vol. 46, No. 6, 2003, pp. 14871493.

[7] J. Bijwe and A. Sharma, "Assessment of Lubricity of Biodiesel Blends in Reciprocating Wear Mode," SAE Paper No. 2004-01-3068.

[8] W. Korbitz, "Biodiesel Production in Europe and North America: An Encouraging Prospect," Renewable Energy, Vol. 16, No. 1-4, 1999, pp. 1078-1083. doi:10.1016/S0960-1481(98)00406-6

[9] X. F. Wang, M. C. Peng and H. L. Wang, "Study on the Optimal Proportion of Diesel/Bio-Diesel/Ethanol," Vehicle Engine, Vol. 177, No. 4, 2008, pp. 84-89.

[10] W. Ji, T. J. Fu, Y. G. Yao, et al., "Experimental Study on Diesel Engine Burning Ethanol-Diesel-Biodiesel Blend Fuel," Transactions of the Chinese Society of Agricultural Engineering, Vol. 3, No. 3, 2007, pp. 180-185. 